\title{
Observatório
}

I ISSN n² 2447-4266

Vol. 4, n. 3, maio. 2018

DOI: https://doi.org/10.20873/uft.2447-4266.2018v4n3p601

\section{OS JORNALISTAS E A \\ DITADURA DA \\ CONEXÃO}

JOURNALISTS AND THE
CONNECTION DICTATOSHIP

LOS PERIODISTAS Y EL DITADURA

DE LA CONEXIÓN

\section{Giovana Mesquita ${ }^{1,2}$}

\section{RESUMO}

O artigo se propõe a refletir sobre como a relação entre jornalistas e o que denominamos Audiência Potente tem provocado complexas alterações no mundo do trabalho do jornalismo, afetando o profissional e a produção noticiosa. Se ao longo do século $\mathrm{XX}$, o jornalismo era caracterizado por uma narrativa produzida por profissionais especializados, hoje a construção dessa narrativa envolve uma audiência, que possui capacidade de ação; de transformação; de amplificação; de propagação e que acaba se envolvendo ou sendo envolvida pelos veículos de referência na produção noticiosa. A relação com essa audiência, que denominamos potente, modifica a rotina produtiva dos jornalistas, obrigando-os a saber lidar com a conversação e também com as cobranças, tudo em tempo real.

\footnotetext{
${ }^{1}$ Doutora em Comunicação pela Universidade Federal de Pernambuco (UFPE), com estágio doutoral na Universidade Pompeu Fabra de Barcelona (Espanha). Coordena o Grupo de Pesquisa Dinâmicas do Jornalismo e integra o Grupo Jornalismo e Contemporaneidade. Atualmente é professora adjunta do curso de Comunicação Social na Universidade Federal de Pernambuco(CAA) e da pós-graduação em Comunicação da UFPE. E-mail: giovanamesquita@yahoo.com.br.

${ }^{2}$ Endereço de contato com os autores (por correio): Centro de Artes e Comunicação. Av. Prof. Moraes Rego, s/n, Cidade Universitária. CEP 50670-901. Recife - Pernambuco - Brasil.
} 


\title{
obsevisto \\ I ISSN n² 2447-4266 \\ Vol. 4, n. 3, maio. 2018 \\ DOI: https://doi.org/10.20873/uft.2447-4266.2018v4n3p601
}

PALAVRAS-CHAVE: Audiência Potente; Jornalismo; Jornalista.

\begin{abstract}
The article proposes to reflect on how the relationship between journalists and what we call Powerful Audience has caused complex changes in the work world of journalism, affecting the professional and the news production. If throughout the 20th century, journalism was characterized by a narrative produced by specialized professionals, today the construction of this narrative involves an audience, which has capacity for action; for processing; of amplification; of propagation and that ends up involving itself or being involved by the reference vehicles in the news production. The relationship with this audience, which we call potent, modifies the productive routine of journalists, forcing them to know how to deal with the conversation and also with the charges, all in real time.
\end{abstract}

KEYWORDS: Powerful Audience Journalism; Journalists.

\section{RESUMEN}

El artículo se propone reflexionar sobre cómo la relación entre periodistas y lo que denominamos Audiencia Potente ha provocado complejas alteraciones en el mundo del trabajo del periodismo, afectando al profesional y la producción noticiosa. Si, a lo largo del siglo $\mathrm{XX}$, el periodismo se caracterizaba por una narrativa producida por profesionales especializados, hoy la construcción de esa narrativa envuelve una audiencia, que posee capacidad de acción; de transformación; de amplificación; de propagación y que termina envolviéndose con los vehículos de referencia o siendo involucrado por ellos en la producción noticiosa. La relación con esa audiencia, que denominamos potente, modifica la rutina productiva de los periodistas, obligándolos a saber lidiar con la conversación y también con los cobros, todo en tiempo real.

PALABRAS ClAVE: Audiencia Potente; Periodismo; Periodista.

Recebido em: 12.01.2018. Aceito em: 16.03.2018. Publicado em: 29.04.2018. 


\section{Observatório}

I ISSN n² 2447-4266

Vol. 4, n. 3, maio. 2018

DOI: https://doi.org/10.20873/uft.2447-4266.2018v4n3p601

\section{Introdução}

Desde o final do século $X X \circ$ jornalismo vem passando por transformações que afetam o profissional, a produção noticiosa e a audiência. As alterações vão desde o aproveitamento jornalístico da Internet como meio de difusão, como fonte de informações, como ferramenta de investigação, mas principalmente como possibilidade para efetivação da interatividade tanto com as fontes, quanto com a audiência.

Para nós, a possibilidade para efetivação da interatividade em tempo real com as fontes e com a audiência é a maior transformação porque passa o jornalismo. A facilidade de acesso as chamadas novas Tecnologias da Informação (TICs) fez com que o cidadão comum, por vezes excluído do debate público articulado pelo jornalismo, começasse a intervir no processo de produção de conteúdos para as mídias, disputando visibilidade midiática com as fontes oficiais, que alimentam a pauta jornalística.

Historicamente, o acesso privilegiado à pauta jornalística vinha sendo usufruído pelas fontes oficiais. As demais fontes - movimentos sociais e o cidadão comum de uma maneira geral - que se encontram na periferia da estrutura de poder sofriam, quase sempre, uma exclusão sistemática do debate público articulado pelo jornalismo. Essa exclusão comprometia a representatividade e a legitimidade da representação simbólica que constrói a realidade.

Se ao longo do século $\mathrm{XX}$, ○ jornalismo era caracterizado por uma narrativa produzida por profissionais especializados, no século XXI a construção dessa narrativa envolve uma audiência, que possui capacidade de ação; de transformação; de amplificação; de propagação e que acaba se envolvendo ou 


\section{Observatório}

I ISSN n² 2447-4266

Vol. 4, n. 3, maio. 2018

DOI: https://doi.org/10.20873/uft.2447-4266.2018v4n3p601

sendo envolvida pelos veículos de referência na produção noticiosa. A relação com essa audiência, que denominamos potente, modifica a rotina produtiva dos jornalistas, obrigando-os a saber lidar com a conversação e também com as cobranças, tudo em tempo real.

O artigo se propõe a refletir sobre como a relação entre jornalistas e o que denominamos Audiência Potente tem provocado complexas alterações no mundo do trabalho do jornalismo. O artigo é um fragmento da pesquisa realizada nas redações do Diario de Pernambuco (DP), mais antigo jornal em circulação da América Latina, que fica sediado no Recife (Brasil), e do La Vanguardia (LV), que funciona em Barcelona (Espanha). Dois jornais que são pioneiros em suas cidades, não só na abertura de espaços ditos colaborativos ou participativos, como também na criação de novas editorias, como a de Mídias Sociais (Diario de Pernambuco) e a de Redes Sociais (La Vanguardia), cujo objetivo é envolver a audiência na construção da notícia.

\section{A pesquisa de campo}

Para realizar a pesquisa escolhemos como objetos 0 diariodepernambuco.com, versão digital do Diario de Pernambuco (DP), sediado no Recife, Nordeste brasileiro e o lavanguardia.com (LV), edição digital do diário La Vanguardia de Barcelona(Espanha).

O diariodepernambuco.com é a versão digital do Diario de Pernambuco(DP), jornal fundado em 1825, como um diário de anúncios, no Recife, por Antonino Falcão. Na década de 1930, o jornal foi incorporado pelos Diários Associados, de Assis Chateaubriand. Nos anos 2000, o jornal deixou a 


\section{Observatório \\ I ISSN nº $2447-4266$ \\ Vol. 4, n. 3, maio. 2018 \\ DOI: https://doi.org/10.20873/uft.2447-4266.2018v4n3p601}

região central do Recife e foi para a zona Norte da cidade, reunindo, em um só espaço físico, todos os veículos do grupo(rádio, TV, jornal impresso e Internet).

O lavanguardia.com é a edição digital do diário La Vanguardia, um dos mais importantes jornais de Barcelona. O meio online, que oferece informação em tempo real, 24 horas por dia, integra o grupo espanhol Godó, que detém, desde 1881, a propriedade do diário impresso La Vanguardia, além de outros meios de comunicação. A versão digital do La Vanguardia foi lançada em 1995. Os dois jornais foram pioneiros em suas cidades na abertura de espaços ditos participativos e na criação de novas editorias, como a de Mídias Sociais (DP) e a de Redes Sociais (LV), com o objetivo de envolver a audiência na construção da notícia.

A escolha de uma abordagem etnográfica para a realização da pesquisa de campo, na forma de uma observação participante, possibilitou reunir e obter sistematicamente os dados e as informações sobre as rotinas de produção que acontecem nos media.

Seguindo Casetti \& Chio (1999), que entendem ser necessário o analista observar a realidade ao vivo, para não correr o risco de ter dados contaminados por mediações, permanecemos pelo período de duas semanas, em cada uma das redações. Procuramos compreender como os veículos de referência incorporam os conteúdos advindos da audiência à sua produção.

Além da entrada no "campo" para observar o dia a dia na redação, realizamos também 11 entrevistas em profundidade com a editora executiva do diariodepernambuco.com, Paula Losada; o subdiretor do lavanguardia.com, Enric Sierra; o editor de Participação do La Vanguardia, Tony Rubies; a editora do Cidadão Repórter - Diario de Pernambuco, Carolina Santos; o editor de 


\section{Obsevisto \\ I ISSN n² 2447-4266 \\ Vol. 4, n. 3, maio. 2018 \\ DOI: https://doi.org/10.20873/uft.2447-4266.2018v4n3p601}

Mídias Sociais do Diario de Pernambuco, Fred Figuerôa; a community manager do La Vanguardia, Patrícia Ventura; além de repórteres de ambos os jornais. As reflexões desse artigo são trazidas a partir das entrevistas feitas com os profissionais dos dois veículos. Manteremos a equipe no anonimato, para evitar constrangimentos relacionados as suas falas. Todas as vezes que necessitarmos colocar a informação verbal repassada pelos entrevistados, identificá-los-emos como periodista 1 , periodista 2 , periodista 3 , periodista 4 e periodista 5 , no caso do lavanguardia.com e como jornalista 1 , jornalista 2 , jornalista 3 , jornalista 4 , jornalista 5 e jornalista 6, no caso do Diario de Pernambuco.

O propósito das entrevistas era sair de abstrações e compreender a relação dos jornalistas com a Audiência Potente, e as mudanças decorrentes dessa relação na produção da notícia.

Entendíamos que a abertura de canais ditos colaborativos ou participativos, bem como a utilização do material produzido pela audiência, em alguns momentos como complementar ao trabalho da redação, não esgotavam a relação audiência-jornalismo. Tínhamos como hipótese de pesquisa que a mudança na produção da notícia surge a partir das novas relações que os veículos passam a estabelecer com a audiência, mediada pelas redes sociais (Twitter e Facebook).

\section{Novas rotinas, novos desafios}

Ainda que a instantaneidade não seja característica da Internet, uma vez que o rádio e a televisão, como bem destaca Morethzsohn (2002), sempre a 


\section{Observatório}

I ISSN n² 2447-4266

Vol. 4, n. 3, maio. 2018

DOI: https://doi.org/10.20873/uft.2447-4266.2018v4n3p601

perseguiram motivados pela competição entre os veículos, na "era do tempo real" a produção da notícia é praticamente instantânea.

Os jornalistas, sobretudo os que trabalham em redações integradas, estão literalmente numa corrida contra o tempo. As consequências dessa rotina frenética, que ainda inclui a relação com a audiência em tempo real, é que o jornalista, além do estresse, da cobrança e da corrida pelo "furo", vê-se, como destaca o periodista 1 (2013, INFORMAÇÃO VERBAL):

num esforço em responder e errando mais. Porque é preciso reconhecer que cometemos mais erros agora do que antes, por essa pressão de querermos ser os primeiros e do público estar exigindo explicação, informações... Tudo isso mudou o trabalho jornalístico na medida em que alguém está fazendo uma notícia e salta um tuíte de algo, e ele deixa o que está fazendo e segue esta pista. Aquilo é o último, o urgente e, muitas vezes, o urgente freia o importante. $E$ isso é uma reflexão que devemos fazer, porque muitas vezes é urgente, mas no final não leva a nada e perdemos tempo aí, mas isso se explica porque o público fica esperando de nós mais informação disso que todo mundo já sabe. Isso mudou radicalmente. Então, há mais estresse, mais erros e a obrigação do jornalista de estar sempre conectado. É mais perigoso!

O jornalista 3 (2013, INFORMAÇÃ̃ VERBAL), do Diario de Pernambuco, fala dessa "ditadura da conexão" a que o profissional está sujeito:

As redes sociais são a última coisa que eu olho antes de dormir e a primeira coisa que eu olho quando acordo. (...) Eu nunca trabalhei tanto extra-oficialmente (...) Oito horas da manhã eu já tenho uma mensagenzinha de alguém... Já tenho uma coisa para resolver... Porque é constante né? As redes sociais não têm um momento.

Além de conectado, o jornalista passa a ter a "autonomia" regulada, não só pelas organizações de mídia, como também pela Audiência Potente, que tem vários canais para apresentar suas versões dos fatos e/ou opiniões. A fala do jornalista 3 (2013, INFORMAÇÃO VERBAL) demonstra um pouco essa regulação: 


\section{Observatório}

I ISSN n² 2447-4266

Vol. 4, n. 3, maio. 2018

DOI: https://doi.org/10.20873/uft.2447-4266.2018v4n3p601

O jornalista é um dos profissionais que respira redes sociais, que se importa com o que se projeta na rede social. Então, sem dúvida, o jornalista, hoje, quando escreve qualquer matéria, ele pensa na matéria dele no dia seguinte na rede social. Não tenho a menor dúvida disso. A não ser que seja uma matéria de muita irrelevância. Mas ele sabe que o primeiro lugar que ele vai ter que responder é nas redes sociais.

Com as redes sociais não faz parte da rotina dos jornalistas, atualmente, apenas as rondas telefônicas e a checagem dos conteúdos que chegam à redação, por e-mail ou cartas. Integra-se à atividade profissional, o acompanhamento do que acontece nas redes sociais. Nesse trabalho, cada jornalista vai montando uma rede formada pelo que consideram "perfis de credibilidade". A periodista 3 do La Vanguardia (2013, INFORMAÇÃO VERBAL) explica como atua:

Sigo jornalistas, agências, meios internacionais, meios nacionais. Também perfis institucionais, de esportistas e de políticos... Disse que vejo coisas no Twitter, mas também é verdade que muita gente nos diz muitas coisas aqui na conta do La Vanguardia (Twitter). Aqui as pessoas dizem que aconteceu isso e isso! Creio que cada jornalista deve seguir as suas fontes e as pessoas que lhe interessam para sua seção. É isso o que realmente pode fazer nas redes sociais um meio muito grande, se cada jornalista entender o valor que tem isso. Por exemplo, para o jornalista que cobre Internacional, o Twitter é uma fonte brutal. $\mathrm{O}$ jornalista que cobre Internacional tem que estar no Twitter. Quando Kadafi caiu, as primeiras coisas que obtivemos foi pelo Twitter. $O$ que significa que as redes sociais têm muito mais valor pela possibilidade de trazer para nós coisas que estão distantes.

No Diario de Pernambuco, o jornalista 3 (2013, INFORMAÇÃO VERBAL) também tem toda uma metodologia para trabalhar com as redes sociais:

As pessoas funcionam como funis da notícia, não é? Então sempre tem gente que vai ler. í tem perfis de jornalistas, como o cara do Mídia Mundo que analisa capas de jornais... Então, você tem gente que vai buscar informação e já traz o filtro para mim. Então não vou precisar entrar todo dia no site da Folha de São Paulo. Eu já não entro mais em 


\section{Observatório}

I ISSN n² 2447-4266

Vol. 4, n. 3, maio. 2018

DOI: https://doi.org/10.20873/uft.2447-4266.2018v4n3p601

nenhum site, praticamente. A minha pista de decolagem para as notícias é o Twitter e o Facebook. Eu estando ali, eu sei que o que importa está ali. Então, eu abro a Folha de São Paulo através de um link que alguém colocou. Aí eu tenho plena segurança que o que me interessa está ali. Até porque eu também vou dar uma olhada no Trending Topic. Se tiver alguma coisa fora do normal, vou clicar para entender o que é aquilo.

Casero e Marzal (2011) reconhecem que o jornalismo mudou e, consequentemente, a forma como ele se faz. Assim, para um determinado acontecimento ser transformado em notícia, segundo os autores, não basta seguir a fórmula e contentar-se em responder apenas algumas questões básicas dos antigos manuais jornalísticos. Para nós, uma mudança importante, que observamos na pesquisa, é que se anteriormente, na produção da notícia, o jornalista presumia uma audiência, hoje as empresas se baseiam também no que se comenta em redes sociais, a exemplo de Twitter e Facebook, para produzir notícia. Como relata o periodista 1 (2013, INFORMAÇÃO VERBAL):

Na redação web, fazemos reunião a cada três horas. Na web há quatro responsáveis: da informação, da participação, do multimeio e das redes sociais. Reúnem-se e vão vendo como está fluindo a informação, se há novidade, se os leitores estão "empurrando" um tema ou outro, se têm mais interesse em um tema que outro. Eu também estou nessas reuniões. E a partir daí tomamos as decisões, constantemente. E essa temperatura que tomamos constantemente da Web é levada para o papel. E então se diz: alerta, há um tema que está quente nas redes e quiçá deveríamos tratá-lo no papel. E então, no papel, há duas reuniões no dia. Uma pela manhã e outra pela tarde, além das reuniões bilaterais, porque no papel há três subdiretores, que têm abaixo deles várias seções. Os subdiretores despacham com essas seções e nessas reuniões também vão se dando as indicações a partir dessas temperaturas que se toma do ambiente. Aí vão se canalizando os conteúdos. (...) Portanto, sempre estamos monitorando e observando o que sucede na rede social.

O jornalista 3 (2013, INFORMAÇÃO VERBAL) do Diario de Pernambuco entende que as redes sociais são um "termômetro", no qual se pode medir a 


\section{Observatório}

I ISSN n² 2447-4266

Vol. 4, n. 3, maio. 2018

DOI: https://doi.org/10.20873/uft.2447-4266.2018v4n3p601

imagem do jornal junto à audiência, o que dificulta posturas mais conservadoras do veículo de comunicação. Para ele, "as redes sociais não são a voz do país. Mas gritam. Elas influenciam muito qualquer postura mais conservadora nossa".

Essa voz da audiência redefine como o jornalista faz a escolha do que será noticiado e qual enquadramento será privilegiado. Se, antes da Web 2.0, o jornalista presumia uma audiência, trazendo conteúdos que, na sua intuição, eram de interesse dela, hoje as empresas se baseiam no que se comenta em redes sociais, a exemplo de Twitter e Facebook, para produzir notícia. Como relata a jornalista 3 (2013, INFORMAÇÃO VERBAL) do Diario de Pernambuco:

Se alguma coisa que a gente não tem estiver estourada, aí a gente vai atrás, e vai pedir: "Olhe, a gente tem isso no site? Não tem?". Então eu ligo pra minha equipe aqui, se eu estiver em casa, e a equipe vai pedir pro site fazer. E acontece muito. (...) Pronto, recentemente teve uma que até hoje está tendo desdobramentos. É a questão da Sony ter lançado o Playstation a quatro mil reais. Isso veio das redes sociais e foi bater na capa do jornal.

Essa manifestação explícita do que interessa à audiência, não mais de uma forma presumida pelos jornalistas, possibilita que a redação saiba melhor em que temas "apostar".

Com a potência da audiência nas redes sociais, as empresas passam a agregar novos critérios à escolha do que será definido como notícia. Dentre esses critérios está o Trending Topics. O periodista 1 (2012, INFORMAÇÃO VERBAL) exemplifica:

(...) ontem detiveram o que foi presidente dos patronos da Espanha. Isso gerou muito debate e na hora de fazer a capa, à noite, levamos em conta que este tema tinha sido muito relevante, estava sendo Trending Topics. Então dissemos: temos que colocar na capa. E o que 


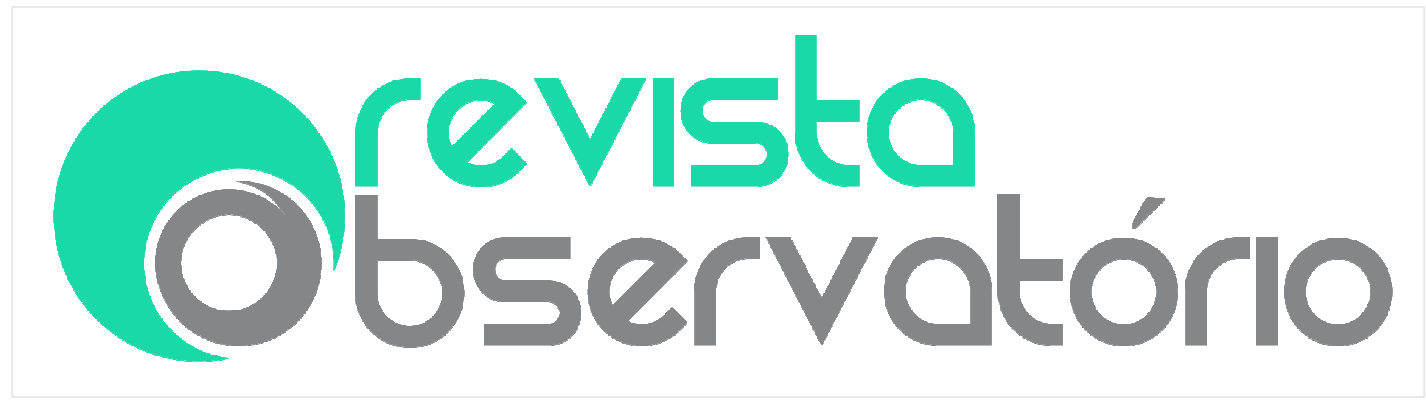

I ISSN n² 2447-4266

Vol. 4, n. 3, maio. 2018

DOI: https://doi.org/10.20873/uft.2447-4266.2018v4n3p601

\begin{abstract}
mais colocar na capa? Outra coisa que estava sendo Trending Topics era isto destas crianças (real baby), então dissemos: vamos colocar na capa. Isso antes não acontecia. Antes era a intuição, outros critérios. Agora, não é esse o único critério, mas influi fortemente e estamos muito agradecidos, porque antes era uma loteria. Acertavas ou não acertavas. Era uma loteria. Afirmavas: minha intuição me diz que esse tema interessa muito. Agora não! Agora sabemos de certo que este tema interessa. Não há dúvida e logo acabas decidindo se vais com esse tema, ou não vais, mas sabes certamente que esse tema está interessando.
\end{abstract}

A periodista 3 confirmou, durante nossa entrevista, que na reunião de pauta, que acontece diariamente entre $12 \mathrm{~h}$ e $12 \mathrm{~h} 30$ (suspensa no meu período de observação), ela "entra com os Trending Topics" para balizar as decisões sobre quais temas o jornal vai destacar.

Segundo a periodista 3 (2013, INFORMAÇÃO VERBAL), nessa relação com as redes sociais, além dos Trending Topics podem surgir notícias a partir de:

\begin{abstract}
Uma declaração de um político, que sendo muito polêmica, sempre vai gerar uma conversação posterior nas redes sociais. Pois eu observo isso e, (...) quando posso, faço uma notícia a partir das reações nas redes sociais. Por exemplo, essa notícia (As palavras de Vert causam reação massiva nas redes sociais) foi muito viral, muitos likes, muitos tuítes, muitos compartilhamentos. Então fiz essa notícia com as reações das pessoas importantes, por exemplo, políticos, opinadores, jornalistas e outros.
\end{abstract}

Já o jornalista 3 (2013, INFORMAÇÃO VERBAL) ressalta que o Diario de Pernambuco, por exemplo, "passou a dar muito mais cobertura do noticiário a questões de adoção, de violência contra animal, de coisas relacionadas a animais, por conta das redes sociais". Ele explica que esses temas são garantia de audiência boa e, ainda por cima, são bons para a imagem do jornal.

Por outro lado, a insatisfação da audiência com a cobertura feita pelo jornal leva à quebra do "contrato de leitura" com o veículo. Por meio desse 


\section{Observatório}

I ISSN n² 2447-4266

Vol. 4, n. 3, maio. 2018

DOI: https://doi.org/10.20873/uft.2447-4266.2018v4n3p601

"contrato" ficava implícito que a audiência concordava, ou pelo menos aceitava, o filtro seletivo realizado diariamente pelos jornalistas. Filtro que produz um modo de leitura da realidade social. Travancas (2010) lembra que, com o "contrato de leitura", o público não se dá conta do que ficou fora do seu noticiário e de como o que entrou foi selecionado. Ele dá ao jornalista "carta branca" para, a partir de seus critérios e hierarquias, selecionar as informações que ele, leitor, precisa ou deseja saber. No entanto, com a popularização da Internet e o surgimento da WEB 2.0, a audiência além de questionar o "contrato de leitura" (o que podia ser feito também em outro momento) pode aportar outra versão ao que os veículos de comunicação divulgam e à visão de mundo dos jornalistas.

No lavanguardia.com, o monitoramento das redes sociais é ampliado para observar até que ponto o veículo "acerta" no enquadramento. O periodista 1 afirma:

Se temos um enfoque que nossa audiência não gosta, refletimos e dizemos: pois tem razão nossa audiência! Mudamos e fazemos novos conteúdos, mas sempre com uma reflexão prévia, não por impulso. Primeiro refletimos internamente e depois vamos a retificar, vamos mudar a orientação (PERIODISTA 1, 2012, INFORMAÇÃO VERBAL).

A reação à cobertura dos veículos de referência é um das características importantes do que denominamos Audiência Potente.

\section{A construção do conceito da Audiência Potente}

Até chegarmos a proposta de conceituação da Audiência Potente (2014), referimo-nos a esse cidadão, como mediador público. São os coprodutores da notícia que vêm dialogando com os jornalistas que trabalham em várias mídias 


\section{Observatório \\ I ISSN nº $2447-4266$ \\ Vol. 4, n. 3, maio. 2018 \\ DOI: https://doi.org/10.20873/uft.2447-4266.2018v4n3p601}

(Internet, rádio, jornal ou televisão) e, também, com outros cidadãos como ele (VIZEU \& MESQUITA, 2011).

Em outro trabalho, observamos que esse conteúdo da audiência é mais "aceito" pelos veículos de comunicação de referência, quando se refere a eventos de crise, que dada a sua imprevisibilidade dificulta a cobertura pelas equipes jornalísticas (MESQUITA, 2010).

À medida que a investigação ia aprofundando-se ficava mais evidenciado que o conceito de audiência elaborado pelas teorias de comunicação de massa perde, a cada dia, algo de seu sentido em entornos digitais marcados pela diluição dos papéis de consumidores e produtores, pela personalização dos conteúdos, pelo consumo assincrônico e pelo intercâmbio muitos-muitos (SCOLARI, 2008).

Bowman \& Willis (2005) lembram que a ideia de introduzir a audiência no processo noticioso para obter novas perspectivas ou converter os leitores em repórteres ou comentaristas não é nova. No começo dos anos 1990, sobretudo nos Estados Unidos, os jornais experimentaram a ideia do Jornalismo Cívico, que buscava a participação dos leitores e das comunidades em forma de sessões de grupo, enquetes e reação às histórias noticiosas diárias.

Após essa experiência, ainda no final da década de 1990, foram tomando forma as ideias de incluir a colaboração dos cidadãos para informar sobre temas que os meios tradicionais ignoram. Entendia-se que era uma nova forma de fazer jornalismo, realizada por não profissionais e contraposta ao jornalismo tradicional e analógico, feito por jornalistas. Surgia a denominação: Jornalismo Cidadão (BOWMAN \& WILLIS, 2003). 


\section{Observotório \\ I ISSN n² 2447-4266 \\ Vol. 4, n. 3, maio. 2018 \\ DOI: https://doi.org/10.20873/uft.2447-4266.2018v4n3p601}

Embora também não seja consenso, há um reconhecimento de que as reportagens de crises, consolidadas pelas imediatas consequências do Tsunami no Sul da Ásia, em dezembro de 2004, tenham sido um momento decisivo, como observa Allan (2009), para o termo Jornalismo Cidadão figurar no mundo jornalístico.

O envolvimento da audiência no âmbito da comunicação, após o que se denominou Web 2.0, varia muito, dependendo de suas necessidades e motivações básicas. No papel de produtora e receptora de informações, a audiência, para alguns teóricos, ameaçava a atividade jornalística na medida em que tinha acesso aos meios de produção para participar da configuração da realidade. Mas apesar das muitas discussões nesse momento, os autores só conseguiam convergir para o entendimento de que há uma mudança nas relações entre os veículos de comunicação e a audiência, já que esta última, além de ativa (BARKER, 1999) tem, agora, acesso aos meios de produção de conteúdos. Vale destacar as contribuições teóricas de Singer; Hermida; Domingo; Heinonen; Paulussen; Quandt; Reich; Vujnovic (2011) sobre as temáticas participação nos meios de comunicação e o papel das redes sociais. Autores como Bowman \& Willis (2003), Bruns (2005), Madureira (2010) e Espiritusanto (2011) catalogaram alguns níveis de envolvimento da audiência dentro do ecossistema informativo, e alguns deles são relevantes para a caracterização do que pretendíamos definir como Audiência Potente.

Para Bowman \& Willis (2003) há diferentes possibilidades de envolvimento da audiência na construção do noticiário. Segundo os autores, a audiência "participa" da checagem dos fatos; faz o registro do flagrante de um acontecimento; a complementação da apuração da informação jornalística; e a 


\section{Observatório}

I ISSN n² 2447-4266

Vol. 4, n. 3, maio. 2018

DOI: https://doi.org/10.20873/uft.2447-4266.2018v4n3p601

produção open source de notícias, com a revisão e complementação por pares. Bowman \& Willis (2003) ainda incluem, nesse processo de envolvimento da audiência, os modelos de transmissão ao vivo de áudio e vídeo, a publicidade colaborativa e o gerenciamento de conhecimento.

Espiritusanto (2011) destaca alguns níveis de "participação" dentro do ecossistema informativo que são relevantes para a construção do nosso conceito de Audiência Potente. Um desses primeiros níveis considerados por Espiritusanto (2011, p.15), diz respeito à atuação da audiência nas redes sociais:

Os usuários podem dizer sobre una notícia "gosto", e estão participando; podem comentá-la, e essa participação aumenta e se amplia. Mas também podem votar nos diferentes meios nos quais há hierarquização de noticias (Digg, Menéame...). Se temos em conta que a hierarquização da informação é (ou era) uma das funções dos meios de comunicação e do jornalista, aqui nos encontraríamos com que os usuários estão realizando, na atualidade, um trabalho que até agora correspondia ao jornalista tradicional.

A audiência, para Espiritusanto (2011, p.15-16), também pode "trazer material a um meio, criar meios próprios ou compartilhar conteúdos com outras pessoas"; além disso, pode converter-se em "jornalistas cidadãos". No que considera um grau maior de implicação, Espiritusanto (2011) afirma que a audiência pode se converter em vigilante dos governos e dos meios de comunicação. Por fim, em sua tipologia da "participação", Espiritusanto (2011, p.16) considera que há "jornalistas cidadãos que sabem como fazer chegar a informação de uma situação concreta a agenda internacional" e os que "decidem informar sobre os pequenos e grandes acontecimentos cotidianos surgidos em sua comunidade, a seus vizinhos, e aos que vivem dentro da comunidade" (ESPIRITUSANTO, 2011, p.16). 


\section{Observatório \\ I ISSN n² 2447-4266 \\ Vol. 4, n. 3, maio. 2018 \\ DOI: https://doi.org/10.20873/uft.2447-4266.2018v4n3p601}

Compartilhamos com Espiritusanto (2011) a ideia de que a audiência pode, graças à tecnologia que tenha a seu alcance e ao uso que saiba fazer dela, atuar no registro fotográfico, de vídeo, de texto ou de áudio, assim como pode oferecer uma enorme contribuição à democracia, na medida em que atua como vigilante do poder ou dos meios de comunicação. Apesar disso não consideramos que ela desempenhe o papel de jornalista. Assim, uma das primeiras afirmativas referentes à Audiência Potente, é que ela, embora se integre cada vez mais ao campo jornalístico e contribua com o jornalismo, não é jornalista. A tentativa de fazer essa breve revisão sobre o envolvimento da audiência, longe de esgotar as pesquisas sobre o tema, teve o intuito de esclarecer porque os estudos anteriores, embora tragam importantes contribuições, não contemplam a nossa hipótese da Audiência Potente.

\section{A Audiência Potente e suas capacidades}

Denominamos Audiência Potente esse novo agente que se envolve ou é envolvido nos processos, práticas e nas rotinas jornalísticas, possuindo: capacidade de transformação; força de propagação da informação; capacidade de ação; e capacidade de amplificação (MESQUITA, 2014).

A capacidade de transformação pode ser observada na atuação da Audiência Potente, quando ela traz novos agentes para o universo midiático, num embate para que outros olhares sejam veiculados pelos meios de comunicação de referência. Dito de outra forma, a Audiência Potente vem modificando não só a pauta dos jornais, rádios e emissoras de televisão colocando na esfera midiática novos assuntos, quebrando a hegemonia das vozes institucionalizadas que são fontes para o jornalismo, e alterando alguns 


\section{Observotório \\ I ISSN nº $2447-4266$ \\ Vol. 4, n. 3, maio. 2018 \\ DOI: https://doi.org/10.20873/uft.2447-4266.2018v4n3p601}

valores-notícia - , como também as relações veículos-consumidores da informação. A capacidade de transformação se dá ainda quando a audiência muda sua forma de ação e seu comportamento ao longo do tempo. É importante ressaltar que a audiência pode sempre usar uma ou mais de uma das suas capacidades. Uma hora a audiência pode ser reativa, outra hora pode ser amplificadora, ou mesmo a combinação de todas essas características. No entanto, a Audiência Potente pode modificar ao longo do tempo as suas características e capacidades dependendo de condições culturais, econômicas, sociais, tecnológicas, dentre outras.

Mas toda essa mudança que a Audiência Potente vem produzindo na relação com os veículos de comunicação só é vultuosa por três aspectos que consideramos em nossa conceituação: a capacidade de propagação da informação, não necessariamente notícia; a capacidade de ação, possibilitada pelo acesso aos meios de produção e a capacidade de amplificação.

Com a Internet, os novos dispositivos tecnológicos (celulares, tablets) e as redes sociais, a Audiência Potente consegue propagar um maior número de informações num menor espaço de tempo, sem que emita nenhum juízo de valor sobre aquela informação. $\mathrm{O}$ que antes poderia significar anos, agora depende de um click na tecla enviar de um computador ou de qualquer dispositivo móvel conectado a Internet.

A maioria das redes sociais, como destaca Telles (2010), contém o conceito de um grupo - um conjunto de pessoas unidas com um interesse comum. Os membros do grupo interagem compartilhando informações, discutindo ou enviando mensagens privadas para um determinado integrante, e podem ainda promover mobilizações, tanto presenciais, como também no 


\section{Observatório}

I ISSN n² 2447-4266

Vol. 4, n. 3, maio. 2018

DOI: https://doi.org/10.20873/uft.2447-4266.2018v4n3p601

sentido de formar um grupo de pressão, que não vai necessariamente às ruas, mas que na própria rede exerce uma influência sobre instituições ou empresas. E aí entra nosso segundo argumento para a conceituação da Audiência Potente: sua capacidade de amplificação.

Espaços essencialmente conversacionais, as redes sociais têm a possibilidade de amplificar as vozes da audiência. Portanto, ao usar a capacidade de amplificação, a audiência ressignifica o conteúdo, por meio de comentários, opiniões e novos olhares sobre o assunto, que é reverberado nas redes, oferecendo um extrato do que querem e do que pensam esses cidadãos e cidadãs que se envolvem com os meios de comunicação. A capacidade de amplificação pode constituir-se em uma expressão da inteligência e da consciência coletivas.

Por fim, a capacidade de ação pode ser entendida como a possibilidade da Audiência Potente testemunhar e coproduzir conteúdos, além de vigiar (denunciando atividades públicas ou privadas ilegais, abusivas ou insatisfatórias) e reagir (a notícias que violem valores sociais e ou culturais). Há nessa capacidade uma mistura do interesse público com o interesse da audiência.

\section{Considerações Finais}

A sociedade em rede trouxe mudanças nas formas de organização social e consequentemente no Jornalismo. Mudanças que trazem desafios, que nos obrigam a pensar sobre conceitos novos e velhos que se emaranham nessa teia informacional. 


\section{ISSN n² 2447-4266 \\ Vol. 4, n. 3, maio. 2018 \\ DOI: https://doi.org/10.20873/uft.2447-4266.2018v4n3p601}

No caso dos jornalistas, as transformações os levaram a converter-se em produtores-gestores polivalentes da informação em diferentes suportes e formatos (SCOLARI,2008). E essa polivalência muitas vezes representa uma precarização do trabalho.

As exigências para o profissional não são mais lidar com a instantaneidade, com a busca pelo "furo", mas em como lidar com uma audiência cada vez mais ativa. Com acesso, habilidade de uso dos dispositivos tecnológicos, conectividade e a possibilidade de interatividade, a Audiência Potente passa a ter a possibilidade não só de ressignificar as mensagens que recebe, como também de se envolver com os veículos de comunicação das mais diversas formas. A capacidade de propagação dessa Audiência Potente tem levado o jornalista, não só a incorporar esses conteúdos que estão nessas redes conversacionais, mas a movimentar ou ativar essas redes para "ter" os "olhares" desse novo agente, que não é necessariamente uma fonte institucionalizada do jornalismo. Adghirni (2012, p.66) diz que "trata-se de uma situação de interatividade e de reflexividade inédita na história, que obriga os produtores de conteúdos a ajustarem rapidamente sua produção para os leitores e para os concorrentes".

Diante dessa Audiência Potente, os jornalistas estão sob uma "ditadura da conexão", que extrapola o tempo de sua atividade na empresa de comunicação. Ao lidar com espaços conversacionais, os jornalistas se veem permanentemente em contato com uma audiência que exige respostas, que quer ter dúvidas esclarecidas, erros consertados, tudo isso a qualquer hora, estando o jornalista onde for. 


\section{Observatório \\ I ISSN n² 2447-4266 \\ Vol. 4, n. 3, maio. 2018 \\ DOI: https://doi.org/10.20873/uft.2447-4266.2018v4n3p601}

São novos cenários que se configuram, e que exigem do Jornalismo, como destaca Chaparro (2007), descobrir, tomar consciência, se preparar para exercer os novos papéis que the cabem, em uma sociedade movida pelas energias da informação e pelos embates discursivos de instituições e pessoas que sabem o que dizer, como dizer e quando dizer.

\section{Referências}

ADGHIRNI, Z. L. Mudanças Estruturais no Jornalismo: travessia de uma zona de turbulência. In: PEREIRA, Fábio; MOURA, Dione; ADGHIRNI, Zélia (Org.). Jornalismo e Sociedade Teorias e Metodologias. Florianopolis: Insular, 2012.

ALLAN, Stuart. Histories of Citizen Journalism. In: ; Thorsen, Elinar. Citizen Journalism: global perspectives. New York: Simon Cotle General Editor, 2009.

BRAMBILLA, Ana (org.). Para entender as mídias sociais. Volume 1. Licenciada pela Creative Commons. 2011.

BARKER, C. Televisión, globalización e identidades culturales. Barcelona: Paidós, 2003.

BOWMAN, S.; WILLIS, C. Nosotros, el medio. The Media Center, 2003. Disponivel em: http://www.hypergene.net/wemedia/espanol.php >. Acesso em: 05 jun.2012.

CASETTI, F.; CHIO, F. Análisis de la televisión: instrumentos, métodos y prácticas de investigación. Barcelona: Paidós, 1999.

CASERO, A.; MARZAL, J. Periodismo em televisión: nuevos horizontes, nuevas tendências. Zamorra, Espanha: Comunicación Social Ediciones y publicaciones, 2011. 


\section{Observatório \\ I ISSN n² 2447-4266 \\ Vol. 4, n. 3, maio. 2018 \\ DOI: https://doi.org/10.20873/uft.2447-4266.2018v4n3p601}

Espiritusanto, O. \& Rodríguez, P. G. Periodismo Ciudadano: evolução positiva de la comunicación.Madrid: Fundación Telefónica, 2011(tradução nossa). FÍGARO, ROSELI; NONATO, C.; Grohmann, Rafael. As mudanças no mundo do trabalho do jornalista. 1. ed. São Paulo: Atlas, 2013. v. 1. 344 pp.

FIGUERÔA, F. Entrevista concedida pelo editor de Mídias Sociais do Diario de Pernambuco a autora dessa tese. Recife, 2013.

LAGE, Nilson. Conceitos de jornalismo e papéis sociais atribuídos aos jornalistas. Revista Pauta Geral-Estudos em jornalismo,2014.

LOSADA, P. Entrevista concedida pela editora executiva do Diario de Pernambuco a autora dessa tese. Recife, 4 de nov. 2013.

MADUREIRA, Francisco Bennati. Cidadão-fonte ou cidadão-repórter? 0 engajamento do público no jornalismo dos grandes portais brasileiros. 2010 Dissertação(Mestrado em Comunicação) - Universidade de São Paulo, São Paulo, 2010.

MASIP, P.; PALOMO, B. Tecnología y producción de contenidos en periodismo digital. In: CABRERA, M. Á. La evolución tecnológica y los cibermedios en el contexto de la convergencia digital. Sevilla: Comunicación social, 2010.

MESQUITA, G. Interfiro, logo existe: a audiência potente e as novas relações no jornalismo. Tese de doutorado. Recife: UFPE, 2014.

SCOLARI, C. A. Hipermediaciones: elementos para uma Teoria de la Comunicación Digital Interativa. Barcelona: Gedisa, 2008.

SOUZA, K. Entrevista concedida pela repórter da editoria de Mídias Sociais do Diario de Pernambuco a autora dessa tese. Recife, 4 de nov. 2013. 


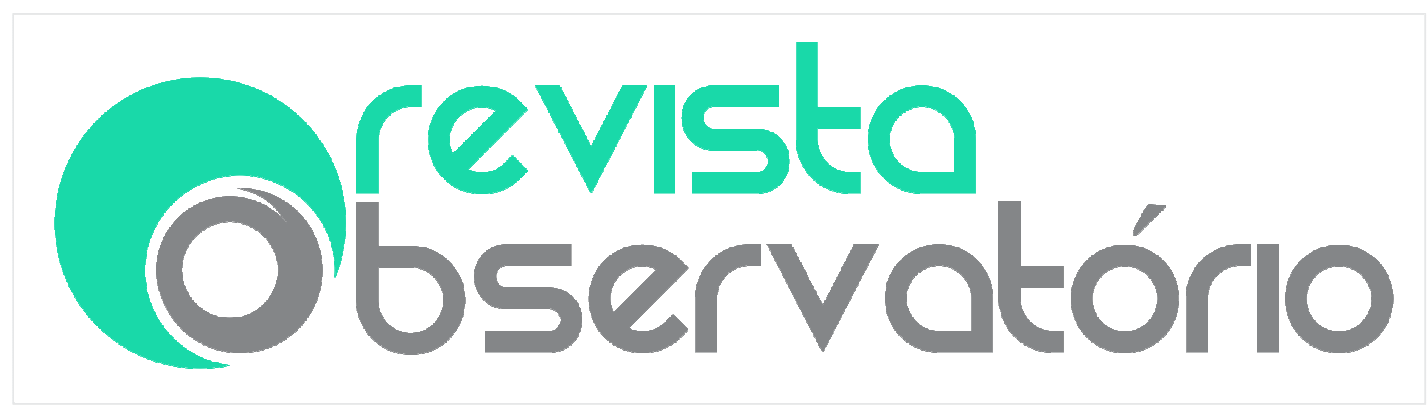

I ISSN n² 2447-4266

Vol. 4, n. 3, maio. 2018

DOI: https://doi.org/10.20873/uft.2447-4266.2018v4n3p601

VENTURA, P. Entrevista concedida pela chefe das redes sociais do Lavanguardia.com à autora do artigo tese. Barcelona, 12, fev. 2013.

VIZEU, A; MESQUITA, G. O Cidadão como mediador público: um novo agente no jornalismo. Revista Estudos em Comunicação, Portugal, n.9, p.329-340,2011. 